\title{
Article \\ Evaluation of Ni-Based Flexible Resistance Temperature Detectors Fabricated by Laser Digital Pattering
}

\author{
Vu Binh Nam (1) and Daeho Lee *(1) \\ Laser and Thermal Engineering Lab, Department of Mechanical Engineering, Gachon University, \\ Seongnam 13120, Korea; vubinhnam@gmail.com \\ * Correspondence: dhl@gachon.ac.kr
}

Citation: Nam, V.B.; Lee, D.

Evaluation of Ni-Based Flexible Resistance Temperature Detectors Fabricated by Laser Digital Pattering. Nanomaterials 2021, 11, 576.

https://doi.org/10.3390/nano11030576

Academic Editor: Alexander Kromka

Received: 25 January 2021

Accepted: 21 February 2021

Published: 25 February 2021

Publisher's Note: MDPI stays neutral with regard to jurisdictional claims in published maps and institutional affiliations.

\begin{abstract}
Temperature sensors are ubiquitous in every field of engineering application since temperature control is vital in operating, testing and monitoring various equipment systems. Herein, we introduce a facile and rapid laser digital patterning (LDP) process to fabricate low-cost, Nibased flexible resistance temperature detectors (RTDs). Ni-based RTDs are directly generated on a thin flexible polyimide substrate (thickness: $50 \mu \mathrm{m}$ ) by laser-induced reductive sintering of a solution-processed nonstoichiometric nickel oxide $\left(\mathrm{NiO}_{x}\right)$ nanoparticle thin film under ambient conditions. The shape of RTDs can be easily adjusted by controlling computer-aided design (CAD) data without using the physical patterning mask while the sensitivity (temperature coefficient of resistance $(\alpha) \sim 3.52 \times 10^{-3}{ }^{\circ} \mathrm{C}^{-1}$ ) of the sensors can be maintained regardless of shape and size of the sensor electrodes. The flexible Ni-based RTDs can operate over a wide temperature range up to $200{ }^{\circ} \mathrm{C}$ with excellent repeatability. Additionally, the Ni-based RTDs respond quickly to the temperature change and can operate in corrosive environments including water and seawater. Moreover, the Ni-based RTDs show a superior mechanical and electrical stability with a negligible resistance change up to a radius of curvature of $1.75 \mathrm{~mm}$. Finally, a tape-pull test demonstrates the robust adhesion of Ni-based RTDs on the substrate.
\end{abstract}

Keywords: laser digital patterning; $\mathrm{NiO}_{x}$ nanoparticle ink; laser-induced reductive sintering; $\mathrm{Ni}$ electrodes; flexible resistance temperature detector

\section{Introduction}

Resistance temperature detectors (RTDs) are extensively adopted as temperature sensors in every field of industrial, consumer, automotive, and medical electronics applications because temperature control and monitoring are vital. The basic principle of RTDs is an increase in electrical resistance of metallic electrodes upon temperature change with a positive temperature coefficient (PTC). Various conventional vacuum-based deposition methods such as sputtering [1,2], chemical vapor deposition (CVD) [3,4], electron beam evaporation [5-7], and thermal evaporator [8,9] have been extensively employed to fabricate RTDs. However, the fabrication of flexible RTDs faces a major challenge for actual utilization since the required high temperature in these fabrication processes can destroy the flexible polymer substrates. On the other hand, the need for customizable sensors is increasing due to the emergence of wearable electronics, artificial skins, health monitoring kits, and soft robotics [10-19] that require more complicated designs and seamless integration between components. To meet these requirements, a new fabrication process to fabricate lightweight and flexible RTDs should be developed, which enables direct deposition of sensor electrodes onto heat-sensitive polymer substrates as well as altering of sensor design in a simple way.

Laser digital patterning (LDP) process of solution-processed thin films has recently emerged as a suitable tool to realize electrode patterning on flexible substrates due to its low thermal stress applied to the substrate [20-32]. In the process, no vacuum-based equipment 
is necessary because thin films can be deposited by spin-coating or blading of nanoparticle (NP) or composite ink. Especially, the pattern designs in the LDP process can be easily controlled simply by changing the computer-aided design (CAD) data instead of altering a physical patterning mask. Au and Ag NPs have been extensively utilized in the early stage of the LDP process because such noble materials are not easily oxidized even in nanoscale, and are easily fused or sintered together to form continuous conductive structures upon laser irradiation owing to their low melting temperature [33-35]. Even though Au [36,37] and Ag [38-40] have been widely employed for the temperature sensing applications, the high price of the noble metals presents a major challenge for practical usage. Hence, using non-noble metals for the LDP process is becoming increasingly important. However, non-noble metal NPs are easily oxidized and exist as metal oxides unless special treatment is applied. Therefore, to form non-noble metal electrodes by the LDP process, metal oxide NPs should be reduced and sintered simultaneously, which is referred to as so-called the laser-induced reductive sintering (LRS) phenomenon [41-43]. Hata et al. reported the fabrication of Cu-based RTDs by reductive sintering of $\mathrm{CuO}$ NPs using femtosecond laser pulses [44]. They also demonstrated that the resistance of the laser-irradiated Cu electrodes displayed a metal-like electrical conductivity behavior with a PTC whereas the resistance of $\mathrm{Cu}_{2} \mathrm{O}$ electrodes showed a semiconductor-like behavior with a negative temperature coefficient (NTC), which could be achieved by controlling the reduction degree of $\mathrm{CuONP}$ thin films during the LRS phenomenon [45]. However, it remains a challenge to use $\mathrm{Cu}$ electrodes as temperature sensors because $\mathrm{Cu}$ is prone to oxidation even under ambient conditions leading to performance fluctuation.

In contrast to $\mathrm{Cu}, \mathrm{Ni}$ has high thermal, chemical stability with silver-like color, thus is used as a component of corrosion-resistant alloys [46-48]. In addition, bulk Ni possesses a relatively higher temperature coefficient of resistance $(\alpha)\left(\alpha_{\mathrm{Ni}}=5.866 \times 10^{-3}{ }^{\circ} \mathrm{C}^{-1}\right) \mathrm{com}$ pared to $\mathrm{Cu}\left(\alpha_{\mathrm{Cu}}=4.041 \times 10^{-3}{ }^{\circ} \mathrm{C}^{-1}\right)$ and other noble metals $\left(\alpha_{\mathrm{Au}}=3.715 \times 10^{-3}{ }^{\circ} \mathrm{C}^{-1}\right.$, $\alpha_{\mathrm{Ag}}=3.819 \times 10^{-3}{ }^{\circ} \mathrm{C}^{-1}$ ) [49]. For these reasons, $\mathrm{Ni}$ has been widely utilized for temperature sensors [50-52]. Atashbar et al. reported the screen printing process to fabricate a Ni-based RTD [50]; Bao et al. demonstrated a Ni-filled binary polymer composite temperature sensor with high thermal cycling stability and tunable temperature range [51]; Yuan et al. developed Ni flexible thermal sensor arrays for underwater applications [52]. However, the limitations such as low thermal stability [51], vacuum-based thin film deposition [52], insufficient adhesion strength of the sensors on the substrate [50], and fixed design patterns [50-52] have room for improvement.

In this study, we introduce a facile and rapid method to fabricate Ni-based flexible RTDs by the LDP process of solution-processed $\mathrm{NiO}_{x} \mathrm{NP}$ thin films. Entire processes covering from synthesis of $\mathrm{NiO}_{x} \mathrm{NPs}$ to the laser process are conducted under ambient conditions. Continuous-wave (CW) laser beam irradiation on the selected areas of the $\mathrm{NiO}_{x}$ thin film coated on very thin $(\leq 50 \mu \mathrm{m})$ flexible substrates induces the reductive sintering phenomenon to generate Ni electrode patterns that are used for RTDs. Various shapes and sizes of Ni-based RTDs can be facilely produced without using physical photomasks. Although the shapes of RTDs are varied, the temperature coefficient of resistance, or sensitivity of the RTDs is maintained, which is advantageous in practical usage by offering design flexibility. The flexible Ni-based RTDs can operate over a wide temperature range up to $200{ }^{\circ} \mathrm{C}$ with fast response and excellent repeatability. Moreover, Ni-based RTDs can detect very small temperature variations (the temperature of the gloved finger) and can operate normally in corrosive environments such as water and seawater. The superior mechanical and electrical stability of the RTD on PI is confirmed through the bending and tape-pull tests.

\section{Materials and Methods}

\subsection{Synthesis of $\mathrm{NiO}_{x} \mathrm{NPs}$ Ink and $\mathrm{NiO}_{x}$ Thin Film Deposition}

$\mathrm{NiO}_{x}$ NPs were prepared following the chemical precipitation method reported in previous literature with several modifications [53]. Nickel(II) nitrate hexahydrate 
$\left(\mathrm{Ni}\left(\mathrm{NO}_{3}\right)_{2} \cdot 6 \mathrm{H}_{2} \mathrm{O}\right)$, polyvinylpyrrolidone (PVP, molecular weight $\left.\approx 10,000\right)$, sodium hydroxide $(\mathrm{NaOH})$, and 1-pentanol were supplied from Sigma-Aldrich, St. Louis, MO, USA. $\mathrm{Ni}\left(\mathrm{NO}_{3}\right)_{2} \cdot 6 \mathrm{H}_{2} \mathrm{O}(0.05 \mathrm{~mol})$ was dispersed in $100 \mathrm{~mL}$ of deionized (DI) water. After the $\mathrm{pH}$ of the solution was controlled to 10 by dropwise adding of $\mathrm{NaOH}$ solution $(10 \mathrm{M})$, the green nickel hydroxide $\left(\mathrm{Ni}(\mathrm{OH})_{2}\right)$ was produced as a colloidal suspension. The colloidal precipitate was separated from the liquid phase by centrifuging at $3000 \mathrm{rpm}$ for $5 \mathrm{~min}$, and the upper liquid phase was discarded. The centrifuging process was repeated twice more after adding some amount of DI water to the solid phase and mixing together. Then, the colloidal precipitate $\mathrm{Ni}(\mathrm{OH})_{2}$ was dried at $80^{\circ} \mathrm{C}$ for $6 \mathrm{~h}$ and calcined at $270{ }^{\circ} \mathrm{C}$ for $2 \mathrm{~h}$ to obtain $\mathrm{NiO}_{x} \mathrm{NPs}$ by the following reaction [54]:

$$
\mathrm{Ni}(\mathrm{OH})_{2} \rightarrow \mathrm{NiO}_{x}+\mathrm{H}_{2} \mathrm{O}
$$

The well-dispersed $\mathrm{NiO}_{x} \mathrm{NP}$ ink was prepared by dissolving $\mathrm{NiO}_{x} \mathrm{NPs}(23.8 \mathrm{wt} \%)$ and PVP (5.60 wt\%) into 1-pentanol (70.6 wt\%) using ultrasonication for $15 \mathrm{~h}$.

Polyethylene terephthalate (PET, thickness $\sim 25 \mu \mathrm{m}$ ) and PI (thickness $\sim 50 \mu \mathrm{m}$ ) were cleaned by ethanol and used as substrates. The surface of the substrates was treated by oxygen plasma (BD-10A High-Frequency Generator, Chicago, IL, USA) to improve the adhesion between the substrates and the NP ink. Uniform $\mathrm{NiO}_{x}$ thin films were prepared on both PET and PI by spin coating at $1000 \mathrm{rpm}$ for $60 \mathrm{~s}$ and dried naturally under the ambient atmosphere for $30 \mathrm{~min}$.

\subsection{Laser Setup for the Laser Digital Patterning Process}

A schematic illustration of the laser system setup for the LDP process using a $532 \mathrm{~nm}$ continuous wave (CW) Nd:YVO laser is illustrated in Figure 1. The focused laser beam irradiated the $\mathrm{NiO}_{x}$ thin films through a galvanometer scanner (HurrySCAN III, Scanlab, Puchheim, Germany) consisting of scan mirrors and a telecentric f-theta lens ( $f=100 \mathrm{~mm})$. The half-wave plate and the polarized beam splitter were installed to control the laser power more precisely. The beam expander was used to enlarge the laser beam entering the telecentric lens installed in the galvanometer scanner to minimize the focused beam diameter. The diameter of the laser beam on the surface of the thin film was measured to be $25 \mu \mathrm{m}$. The laser power was precisely controlled by rotating the half-wave plate while the laser beam path for electrode patterning was controlled by the CAD system (laserDESK, Scanlab, Puchheim, Germany) that is linked to the scanner. The scanning speed was fixed at $50 \mathrm{~mm} \mathrm{~s}^{-1}$ and optimal laser power was found to produce the lowest resistance of a certain shape of the electrode. In this study, the laser power of $20 \mathrm{~mW}$ (power density: $4.1 \mathrm{~kW} \mathrm{~cm}^{-2}$ ) was applied to produce the RTD electrodes on both PET and PI substrates.

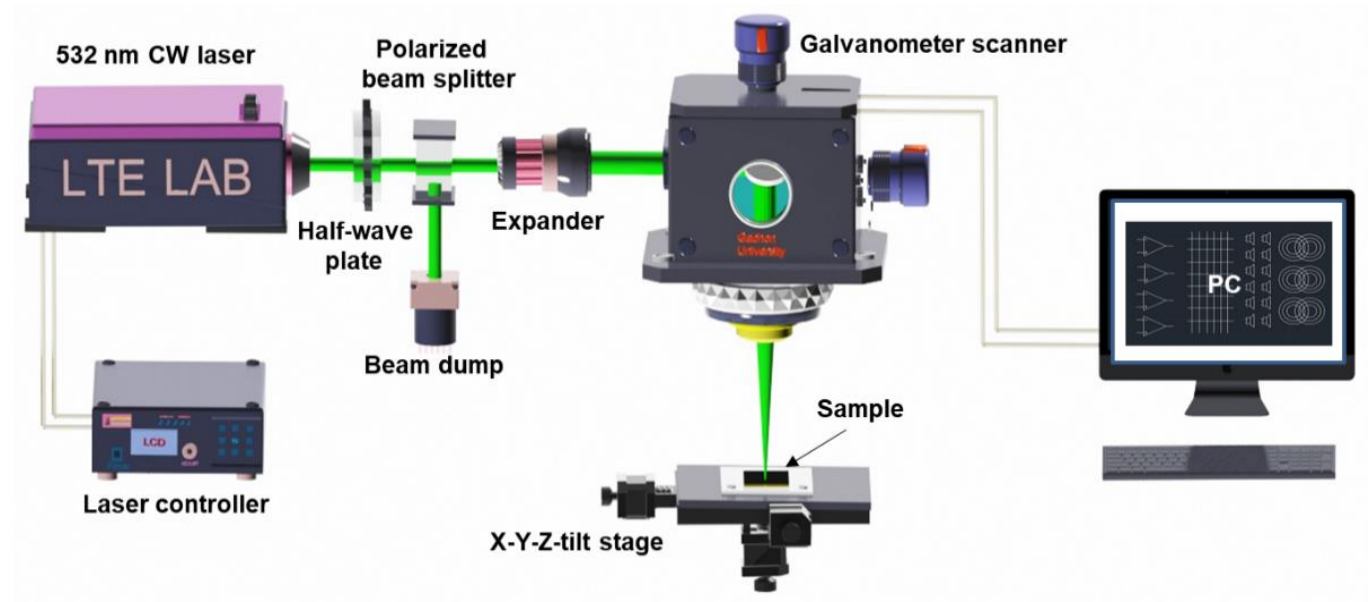

Figure 1. Schematic diagram of the laser setup for the laser digital patterning process to fabricate resistance temperature detectors. 


\subsection{Characterizations}

The sizes of $\mathrm{NiO}_{x}$ NPs were estimated using transmission electron microscopy (TEM, JEOL JEM-2100F, Tokyo, Japan) images. The surface morphology of the sensor electrodes was characterized by scanning electron microscopy (SEM, Hitachi S-4800, Tokyo, Japan) and atomic force microscopy (AFM, Park System XE100, Suwon, Korea). Energy-dispersive X-ray spectrometry (EDS, Hitachi S-4800, Tokyo, Japan) analysis was conducted to investigate the elemental composition of the electrode. X-ray diffraction (XRD, Bruker D8 Advance, Billerica, MA, USA) patterns were recorded for phase identification. The resistance was measured using a multimeter (Agilent U1251B, Santa Clara, CA, USA) while the temperature was precisely controlled by a hot plate (Fisher Scientific, Hampton, NH, USA). The temperature of the hot plate also was monitored by a commercial thermocouple (Type K, EA11A). The resistivity $(\rho)$ of the electrode was calculated using the equation: $\rho=R \cdot(A / l)$, where $R, A$, and $l$ are the resistance, cross-sectional area, and length of the electrode, respectively.

\section{Results and Discussion}

The TEM image (Figure 2a) indicates that the sizes of $\mathrm{NiO}_{x} \mathrm{NPs}$ are in the range of 4-8 nm; their size distribution is displayed in Figure 2a inset. The high-resolution TEM image and the selected-area electron diffraction (SAED) pattern shown in Figure $2 b$ and inset, respectively, demonstrate that $\mathrm{NiO}_{x} \mathrm{NPs}$ have a cubic crystalline structure with the distance of $0.24 \mathrm{~nm}$ between two successive bright fringes which corresponds to the (111) plane of $\mathrm{NiO}_{x}$ [53]. Owing to the well-dispersed NP ink containing ultra-small NPs, smooth and uniform $\mathrm{NiO}_{x}$ thin films can be coated on the substrate by spin-coating (Figure 2c).
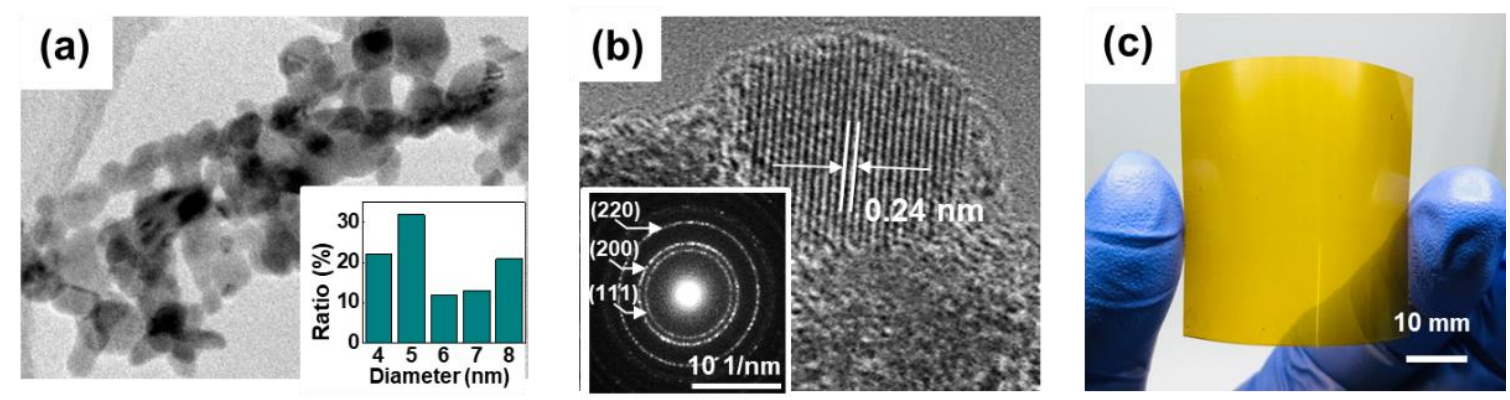

(d)

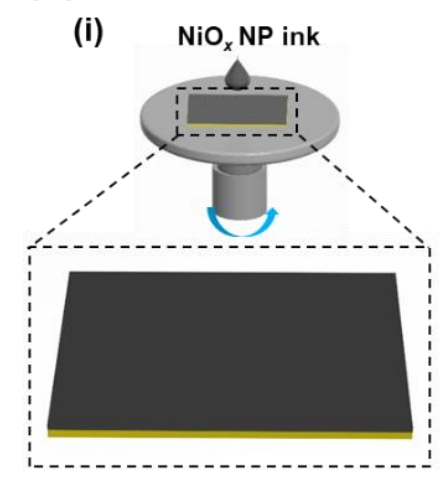

$\mathrm{NiO}_{\mathrm{x}} \mathrm{NP}$ spin coating

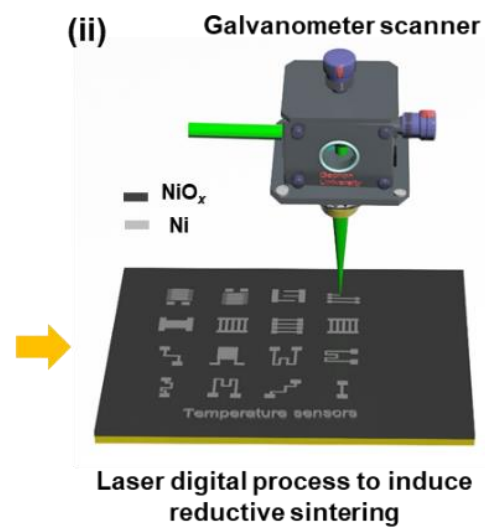

(iii)

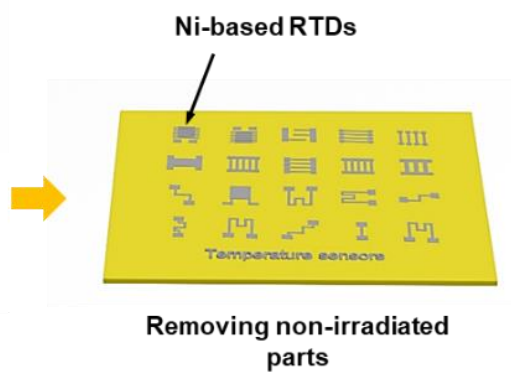

Figure 2. (a) Transmission electron microscopy (TEM) image of $\mathrm{NiO}_{x}$ nanoparticles (NPs). The inset shows the size distribution of the synthesized $\mathrm{NiO}_{x}$ NPs. (b) High-resolution TEM (HR-TEM) image of $\mathrm{NiO}_{x} \mathrm{NPs}$. The inset is the selected-area electron diffraction (SAED) pattern for $\mathrm{NiO}_{x} \mathrm{NPs}$. (c) A uniform $\mathrm{NiO}_{x} \mathrm{NP}$ thin film on a polyimide (PI) substrate. (d) Schematic diagram of the entire processes to produce Ni-based resistance temperature detectors (RTDs). (i) Spin-coating $\mathrm{NiO}_{x}$ thin film on a polyimide substrate, (ii) laser digital process to fabricate Ni-based RTDs. (iii) Removing non-irradiated parts by the washing process. 
The LDP process by which flexible Ni-based RTDs are produced by the LRS phenomenon is illustrated in Figure 2d. First, a $\mathrm{NiO}_{x}$ thin film was deposited on the substrate by spin-coating of the $\mathrm{NiO}_{x} \mathrm{NP}$ ink. After drying the thin film under ambient atmosphere, the selective laser irradiation was applied on the $\mathrm{NiO}_{x}$ thin film to produce Ni electrodes. The mechanism of the LRS phenomenon of PVP-containing metal oxide thin film has been reported in the previous studies $[55,56]$, and can be applied to this work. In short, PVP incorporated in the $\mathrm{NiO}_{x} \mathrm{NP}$ thin film thermally decomposes upon laser irradiation and generates carboxylic acid that reduces $\mathrm{NiO}_{x}$ to $\mathrm{Ni}$. The reduced Ni NPs subsequently sinters together, and form a continuous conductive Ni electrode. Arbitrary patterns of Ni-based RTDs are easily fabricated on the substrate within a short time (Video S1 for the demonstration of the laser process). Last, the non-irradiated $\mathrm{NiO}_{x}$ parts were easily washed away by rinsing with DI water or suitable solution, while the irradiated parts strongly adhered to the substrate (Video S2, Supporting Information). The LDP process applied on the solution-processed $\mathrm{NiO}_{x} \mathrm{NP}$ thin film to fabricate flexible Ni electrodes for RTDs offers the following advantages: (1) the entire processes from the NP synthesis to electrode patterning are conducted under ambient conditions without using any vacuum chamber or gas flow; (2) direct patterning without using a physical photomask is achievable and the shape of electrodes can be easily tuned; (3) thermally vulnerable thin flexible polymers can be employed as substrates since fast heating and cooling nature of localized laser heating minimizes thermal stress exerting on them.

The surface morphology of Ni electrodes on the PI substrate fabricated by the LDP process at the laser power of $20 \mathrm{~mW}$ and scanning speed of $50 \mathrm{~mm} \mathrm{~s}^{-1}$ was characterized using SEM (Figure 3a) and AFM (Figure 3b). The width of the electrode $(30 \mu \mathrm{m})$ is larger than the focused laser beam diameter $(25 \mu \mathrm{m})$ due to heat diffusion across the thin film while the nominal thickness of the electrode is measured to be about $500 \mathrm{~nm}$. It is worthwhile to note that the two axes for the cross-sectional height in Figure $3 \mathrm{~b}$ have different scales. The phase change that occurred by the LRS phenomenon was confirmed by XRD data shown in Figure 3c. Before laser irradiation, the XRD pattern of the thin film shows peaks at $37.2^{\circ}, 43.3^{\circ}$, and $63.2^{\circ}$ corresponding to (111), (200), and (220) planes of the face-centered cubic (FCC) crystal structure of $\mathrm{NiO}_{x}$, respectively (JCPDS file no. 01-089-3493). After laser irradiation, the XRD pattern exhibits peaks at $44.4^{\circ}, 51.7^{\circ}$, and $76.2^{\circ}$ matching with (111), (200), and (220) planes of FCC Ni, respectively (JCPDS file card no. 01-087-0712). The reduction phenomenon was further confirmed by EDS data acquired with the $\mathrm{NiO}_{x}$ thin film and the Ni electrode on the PI substrate as shown in Figure 3d. $\mathrm{Ni}$ content in the laser-irradiated region was higher than that in the non-irradiated region. The carbon peaks in both cases could come from the PI substrate and the PVP that exists in the thin film. Detection of oxygen element in the laser-irradiated region is possibly due to incomplete reduction of $\mathrm{NiO}_{x} \mathrm{NPs}$ and the formation of native oxide layers on the $\mathrm{Ni}$ electrode surface. The resistivity $(\rho)$ of the Ni electrode is calculated to be $975 \mathrm{n} \Omega \mathrm{m}$ which is about 14 times higher than that of bulk $\mathrm{Ni}(69.3 \mathrm{n} \Omega \mathrm{m})$. 
(a)

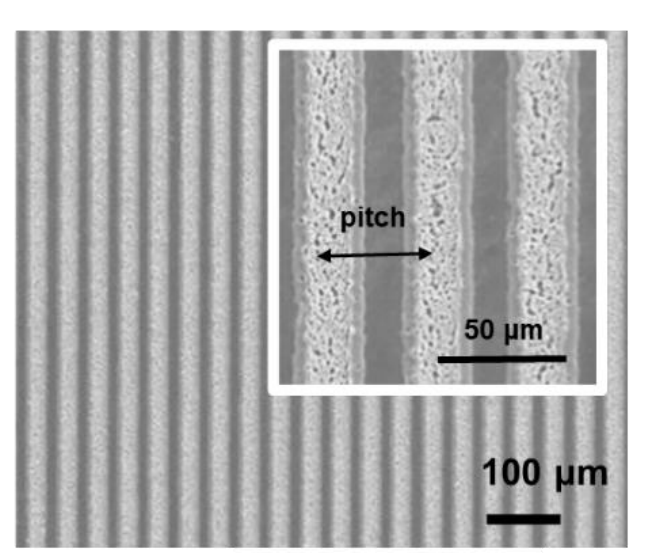

(c)

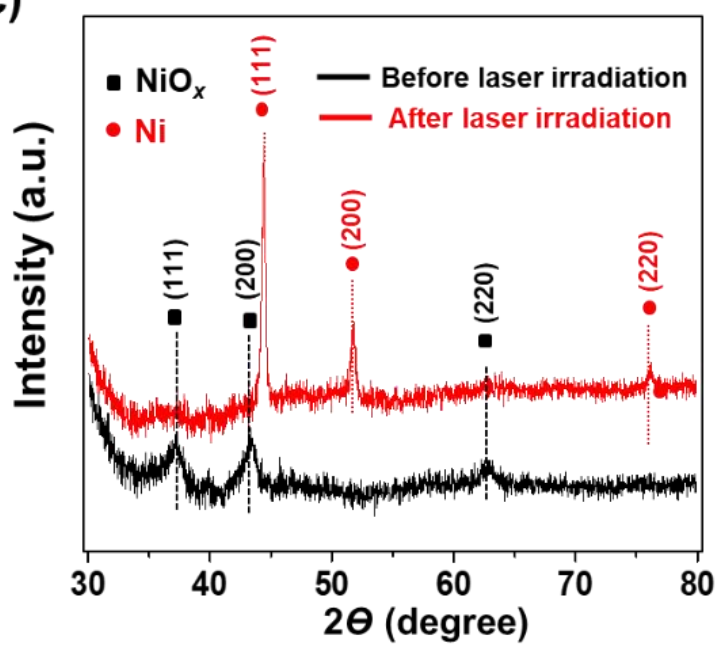

(b)
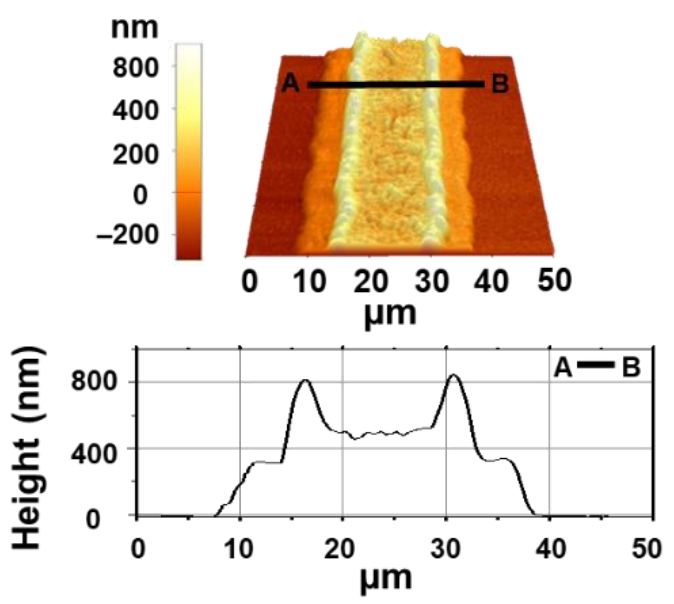

(d)

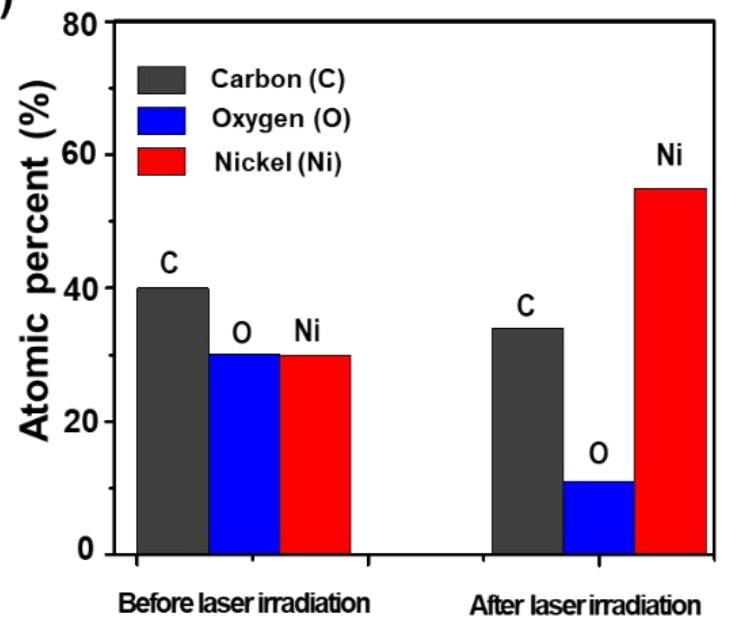

Figure 3. (a) Scanning electron microscopy (SEM) image of multiple Ni electrodes on the polyimide (PI) substrate. The inset is the SEM image at a higher magnification. (b) Atomic force microscopy (AFM) image of a single Ni electrode and the corresponding cross-sectional profile. (c) X-ray diffraction (XRD) patterns before and after the laser-induced reductive sintering of the $\mathrm{NiO}_{x}$ nanoparticle (NP) thin film. (d) Comparison of a chemical composition detected by X-ray spectrometry (EDS) measurement before (left columns) and after (right columns) laser-induced reductive sintering of the $\mathrm{NiO}_{x} \mathrm{NP}$ thin film.

It is demonstrated that arbitrary $\mathrm{Ni}$ electrode patterns could be fabricated on an ultrathin (thickness: $25 \mu \mathrm{m}$ ) PET substrate that has a much lower glass transition temperature $\left(\sim 80^{\circ} \mathrm{C}\right)$ than PI, as shown in Figure 4a. However, the performance of a Ni-based RTD on the PET substrate is limited due to the low glass transition temperature of the substrate. Therefore, the performance analysis of Ni-based RTDs in this study was executed using RTDs fabricated on a PI substrate which possesses high thermal stability [57]. Additionally, the thermal expansion coefficient of PI $\left(\sim 3 \times 10^{-5}{ }^{\circ} \mathrm{C}^{-1}\right)$ [58] is close to that of $\mathrm{Ni}$ $\left(\sim 1.4 \times 10^{-5}{ }^{\circ} \mathrm{C}^{-1}\right)[59]$. Therefore, the possibility of any failure due to a large thermal expansion mismatch between the electrode and the substrate can be excluded. Figure $4 \mathrm{~b}$ shows multiple Ni-based RTDs of various shapes. Areal Ni electrodes without vacant spaces between single Ni electrodes were generated by partly-overlapped parallel scanning of the laser beam with a pitch of $20 \mu \mathrm{m}$ considering that the width of the single $\mathrm{Ni}$ electrode is $30 \mu \mathrm{m}$ as mentioned above. It is worthwhile noting that no protective layer was added to the Ni-based RTD owing to its high thermal stability and strong adhesion on the substrate. The RTD performance of one Ni electrode sample that is selected among various samples shown in Figure $4 \mathrm{~b}$ was investigated by measuring its electrical resistance variation from room temperature $\left(\mathrm{RT}=23^{\circ} \mathrm{C}\right.$ ) to $200^{\circ} \mathrm{C}$. The photo-image and the size detail of the selected sample are displayed in Figure 4c. The sample was placed on a temperature-controlled hot plate and its electrical resistance variation with temperature 
was recorded by a digital multimeter. For each measurement, the temperature of the hot plate was increased to the desired value and then maintained for 5 min to ensure a thermal equilibrium between the sample and the hot plate. The resistance of the sample increases from $1.09 \mathrm{k} \Omega$ at RT to $1.77 \mathrm{k} \Omega$ at $200{ }^{\circ} \mathrm{C}$ during the heating process and returns to its original value during cooling with almost no hysteresis (Figure $4 \mathrm{~d}$ ). More importantly, the relationship between temperature and resistance shows high linearity, which is desirable for an ideal sensor. Compared to the narrow temperature range of $\mathrm{Cu}$-based RTDs due to oxidation issues, the Ni-based RTDs can operate without oxidation problems, which could be attributed to the oxidation-resistant property of the nickel itself and the native oxide layer formed on the electrode surface as discussed above. The temperature coefficient of resistance $(\alpha)$ is a common characteristic parameter that indicates the sensitivity of RTDs, and is described by the following equation [60]:

$$
\alpha=\frac{1}{R\left(T_{0}\right)} \frac{R(T)-R\left(T_{0}\right)}{T-T_{0}}
$$

where $R\left(T_{0}\right)$ is the resistance at a reference temperature $T_{0}$ which is the RT in this study, and $R(T)$ is the resistance at an elevated temperature T. The $\alpha$ value of Ni-based RTD is calculated to be about $3.52 \times 10^{-3}{ }^{\circ} \mathrm{C}^{-1}$, which is higher than those of Au- [36], Ag- [38], Cubased RTD [44], and slightly smaller than that of the commercial platinum ( $\mathrm{Pt}$ ) temperature sensor $\left(3.92 \times 10^{-3}{ }^{\circ} \mathrm{C}^{-1}\right)$ [61]. To assess the reliability of the sensor performance, a thermal cyclic test was conducted by heating and cooling the sensor between RT and $200{ }^{\circ} \mathrm{C}$ for 100 cycles. The resistance variation from $1.09 \mathrm{k} \Omega$ at RT to $1.77 \mathrm{k} \Omega$ at $200{ }^{\circ} \mathrm{C}$ was maintained during the cyclic test (Figure 4e). The response speed of the RTD was evaluated by a latex-gloved finger touching test. The time of the resistance change resulting from the contact and isolation of the gloved finger on the RTD was recorded using a data logger software. Note that the Ag paste was applied on the two ends of the RTD and copper wires were used for the connection between the RTD and the multimeter. As the gloved finger contact the RTD, the resistance increased rapidly and was saturated after 4 s. Upon detaching the gloved finger from the RTD, the resistance returned to its original value after $8 \mathrm{~s}$ as shown in Figure $4 \mathrm{f}$ top and recorded in Video S3 in Supporting Information. In contrast, there was no change in resistance of the RTD in contact with objects of different shapes that were in thermal equilibrium with the room environment, which indicates that the effect of other parameters such as pressure force and contact area was much smaller than that of gloved-finger contact. The resistance variations during the gloved-finger test were converted to the temperature applying equation 2 with $\alpha=3.52 \times 10^{-3}{ }^{\circ} \mathrm{C}^{-1}$ and equilibrium temperature was determined to be $31^{\circ} \mathrm{C}$. To compare the performance of the fabricated Ni-based RTD with that of a commercial thermocouple (Type K, EA11A), the same test was conducted using the commercial thermocouple, and the result is shown in Figure $4 \mathrm{f}$ bottom. The response times and the recovery times for the RTD, which is defined by the time taken by the signal change between a specified low threshold $(10 \%)$ and a specified high threshold (90\%), were indicated in Figure 4f. It is clear that the response and recovery times of the Ni-based RTD were faster than those of the commercial thermocouple, and the Ni-based RTD can precisely measure the temperature of the gloved finger. The fast response of the Ni-based RTD is attributed to the low thermal capacity of the thin substrate $(50 \mu \mathrm{m})$ that allows fast reactions to temperature variations [62]. To demonstrate the high stability of the Ni-based RTD in various environments, the RTD was applied to measure the temperature of tap water and seawater, as shown in Figure $4 \mathrm{~g}$, $\mathrm{h}$, respectively, (see Video S4 in Supporting Information).

To verify the effect of the electrode shape on the temperature-sensing performance, which affects the reference resistance of the electrode, the Ni-based RTD of another shape was selected and the $\alpha$ value of it was examined. The schematic drawing and photo images of the real sample are shown in Figure 5a. The temperature-resistance relationship of the RTD was measure in the same manner and verified that the resistance of the sample changes linearly from $428 \Omega$ at RT to $693 \Omega$ at $200{ }^{\circ} \mathrm{C}$ (Figure $5 \mathrm{~b}$ ) during heating and cooling 
without hysteresis. It is noted that even though the room temperature resistance $(428 \Omega)$ is different from that of the first sample $(1.09 \mathrm{k} \Omega)$ because the dimension of the electrode is different, the $\alpha$ value of the sample $\left(3.50 \times 10^{-3}{ }^{\circ} \mathrm{C}^{-1}\right)$ is almost same as that of the first RTD sample $\left(3.52 \times 10^{-3}{ }^{\circ} \mathrm{C}^{-1}\right)$. The room temperature resistance and corresponding $\alpha$ value of each RTD of different shapes are summarized in Figure $5 \mathrm{c}$. The variation of the $\alpha$ values are within $2.6 \%$ regardless of the room temperature resistance of the RTD. This result shows that the sensitivity of the Ni-based RTD does not depend on the extensive properties of the Ni electrodes, which provides convenience in practical use by offering design pliability.
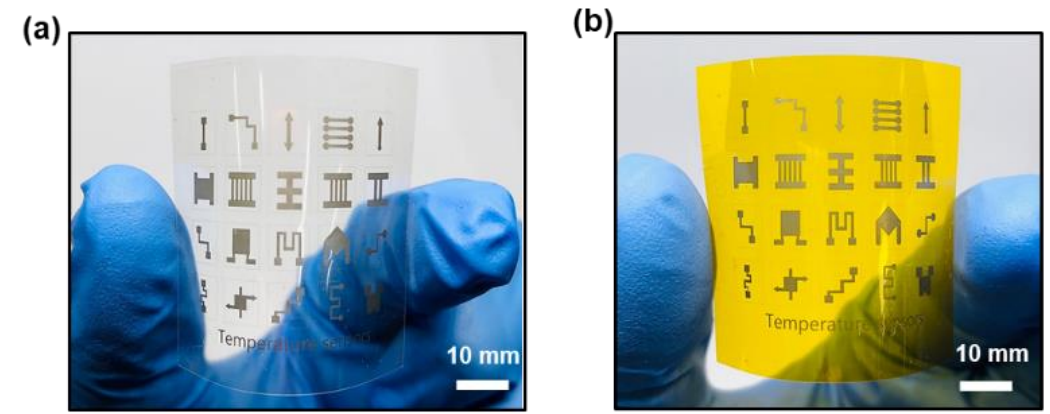

(c)

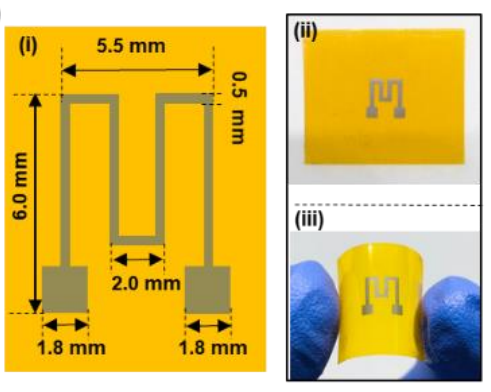

(d)



(e)

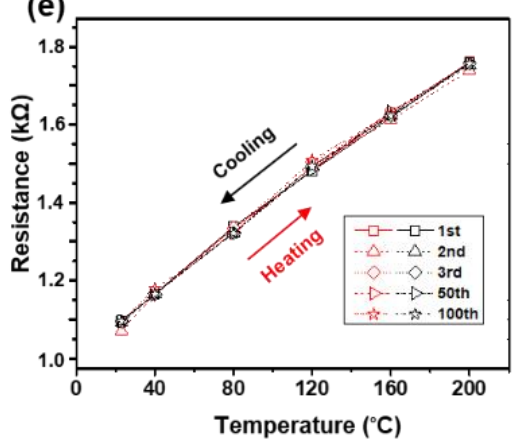

(f)

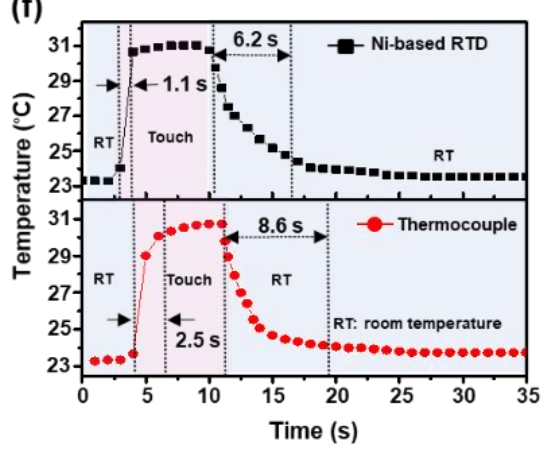

(g)

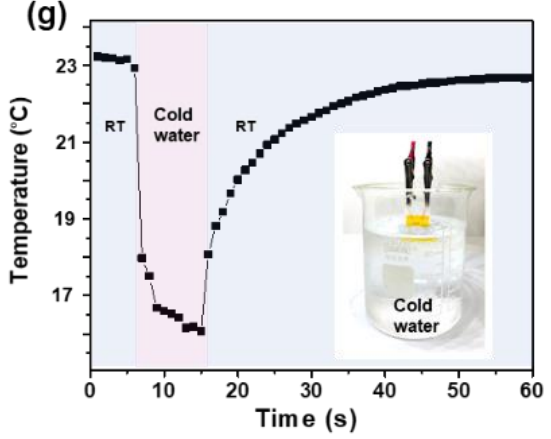

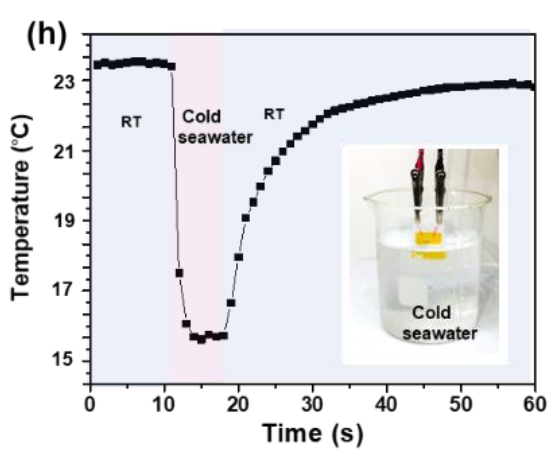

Figure 4. (a) Photo image of Ni-based resistance temperature detectors (RTDs) on a polyethylene terephthalate (PET) substrate. (b) Photo image of Ni-based RTDs on a polyimide (PI) substrate. (c) Schematic drawing of the Ni-based RTD (i) and photo images of the real sample (ii and iii). (d) The resistance variation with temperature showing a linear relationship. (e) 100 thermal cyclic tests of the Ni-based RTD. (f) Responses of the Ni-based RTD (top) and a commercial thermocouple (Type K, EA11A) (bottom) to the latex-gloved finger touching test. Responses of the Ni-based RTD to (g) tap water and (h) seawater. The insets are photo-images of the Ni-based RTD immersing in the water and seawater, respectively. 
(a)



(c)

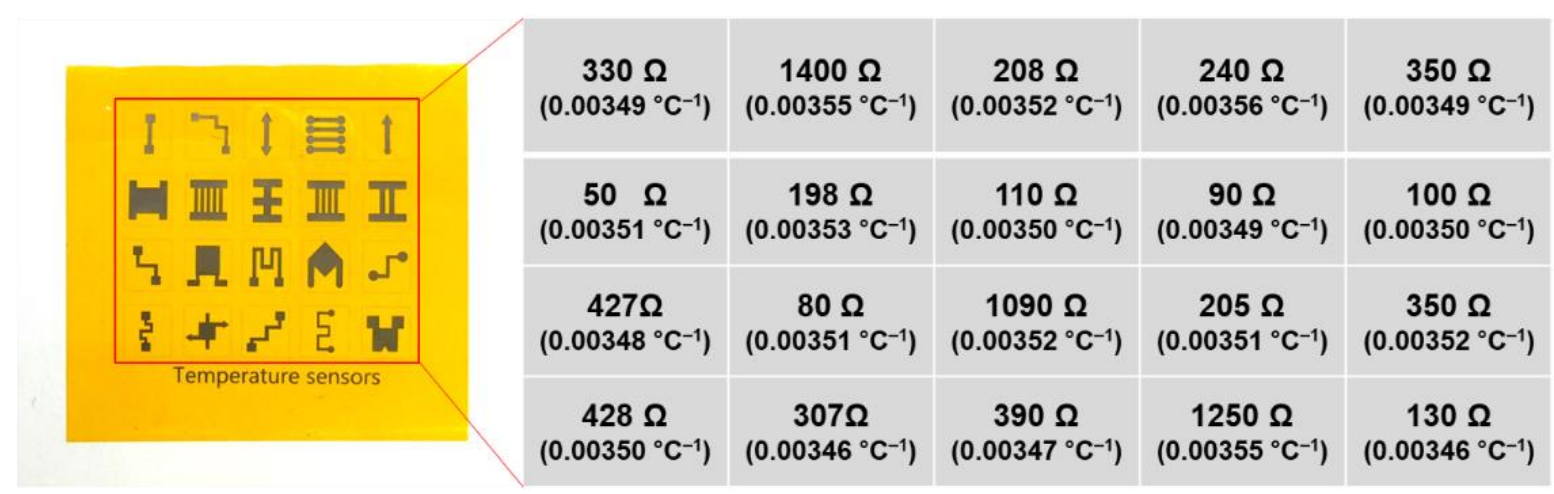

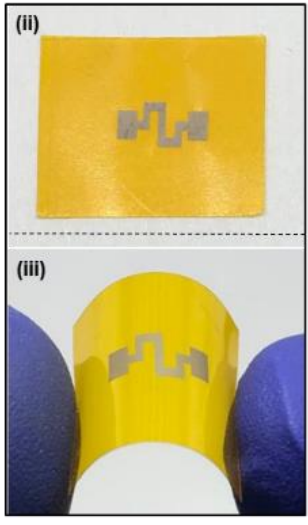

(b)



Figure 5. (a) Schematic drawing of the Ni-based resistance temperature detector (RTD) (i) and photo images of the real sample (ii and iii). (b) The resistance variation with temperature of showing a linear relationship. (c) The reference resistance values and the corresponding temperature coefficient of resistance $(\alpha)$ values of the Ni-based RTDs of various shapes. Each set of values corresponds to the RTD of the designated position.

Mechanical robustness is also an important requirement for flexible RTDs. To examine the mechanical stability of the RTDs, the resistance variation $\left(R / R_{0}\right)$ under various bending radii was measured, where $R_{0}$ is the initial resistance and $R$ is the resistance under the bending condition. The resultant resistance variation $\left(R / R_{0}\right)$ is less than $3 \%$ up to a bending radius of $1.75 \mathrm{~mm}$ indicating a high-level stability under mechanical deformation (Figure 6a). The small resistance variation indicates that there is no permanent damage to the electrodes under bending conditions. The high electrical reliability could be attributed to the lowered bending stress owing to the thin thickness of the sensor $(\sim 50 \mu \mathrm{m})$ as well as the fully-densified microstructure and robust adhesion of the electrode on the substrate. It should be noted, however, that $3 \%$ of the resistance variation corresponds to $8.5{ }^{\circ} \mathrm{C}$ temperature difference based on the given $\alpha=3.52 \times 10^{-3}{ }^{\circ} \mathrm{C}^{-1}$, which is not negligible. Therefore, if the RTD is attached to a surface where the radius of curvature of the surface actively varies over a wide range from $\infty$ (flat) to $1.75 \mathrm{~mm}$, the error in the measured temperature can be that large, which means that the Ni-based RTD on polyimide has some limitation to be applied to such a surface. However, if the curvature variation decreases, the measurement error can be reduced. For example, if the radius of curvature of the surface varies in the limited range such as flat $(\infty) \sim 6.5 \mathrm{~mm}$, and $5 \mathrm{~mm} \sim 3 \mathrm{~mm}$, the errors in the measured temperature are less than $1^{\circ} \mathrm{C}$ and $2{ }^{\circ} \mathrm{C}$, respectively. The mechanical robustness of the Ni-based RTD suggests that the RTD can be applied to curved surfaces without degrading its performance. For instance, the performance of the Ni-based RTD under the bending condition was evaluated by attaching the sensor to the curved surface of a 15-mm-diameter glass vial as shown in the left inset of Figure 6b. The vial was filled 
with $4 \mathrm{~mL}$ of silicon oil to ensure the uniform heat distribution on the curved surface, then placed on a hot plate to increase the temperature. The right inset of Figure $6 \mathrm{~b}$ confirms the uniform surface temperature during heating. The resultant resistance variation with temperature did not change when compared to the change in resistance of the specimen in a flat state (Figure $6 \mathrm{~b}$ ). The adhesion of Ni-based RTDs on the PI substrate was investigated by carrying out a tape-pull test. The tape-pull test was conducted by applying conventional adhesive tape $\left(\mathrm{Scotch}^{\circledR} \mathrm{Magic}^{\mathrm{TM}}, 3 \mathrm{M}\right)$ to the electrode surface and peeling it off subsequently several times. It was confirmed that the Ni-based RTDs did not detach from PI as shown in Figure 6c (see Video S5 in Supporting Information). The strong adhesion of Ni-based RTDs on the PI substrate is attributed to the melting-solidification process that happens at the interface of the electrode and the substrate resulting in interlocking of them as discussed in our previous study [53].

(a)

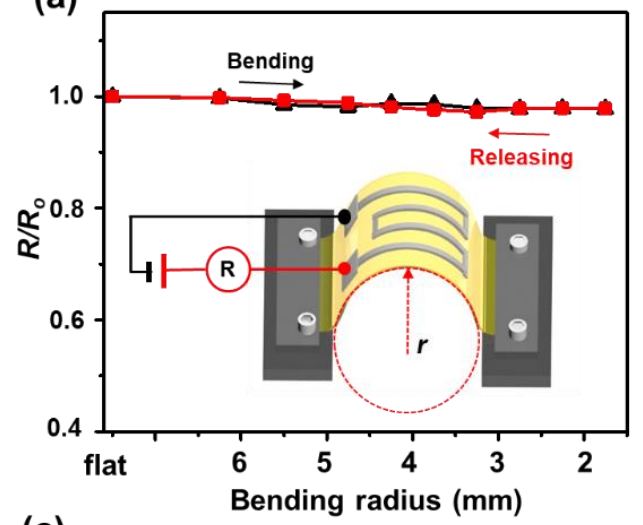

(c)

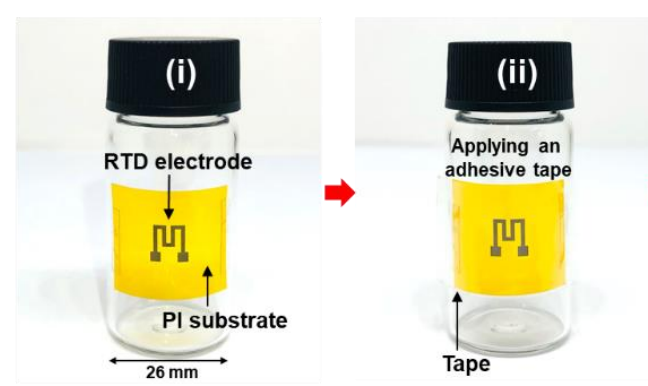

(b)


Figure 6. (a) Relative resistance changes of the Ni-based resistance temperature detector (RTD) under various bending radii. (b) Resistance variation with temperature under the bending condition. (c) Tape-pull test of the Ni-based RTD on the PI substrate. (i) RTD attached on the surface of a 26-mm-diameter glass vial, (ii) applying tape (Scotch ${ }^{\circledR}$ Magic ${ }^{\mathrm{TM}}$ tape, $3 \mathrm{M}$ ) on top of the electrode, (iii,iv) repeating peeling off the tape.

\section{Conclusions}

In summary, we have demonstrated a facile and rapid LDP process to fabricate lowcost, Ni-based flexible RTDs. Ultrasmall $\mathrm{NiO}_{x} \mathrm{NPs}$ were synthesized by a scalable chemical precipitation method, and smooth and uniform thin films could be spin-coated owing to the well-dispersed NP ink. The LRS phenomenon facilitated the generation of various shapes of $\mathrm{Ni}$ electrodes on a thin flexible substrate using the $\mathrm{NiO}_{x}$ thin film without using a physical photomask. The entire processes from the NP synthesis to the laser process were operated under ambient conditions without involving any vacuum process. The flexible Ni-based RTDs exhibited fast response and excellent repeatability in a wide temperature range up to $200{ }^{\circ} \mathrm{C}$. The temperature coefficient of resistance, or sensitivity of the RTD $\left(3.52 \times 10^{-3}{ }^{\circ} \mathrm{C}^{-1}\right)$ was higher than those of $\mathrm{Au}-, \mathrm{Ag}-, \mathrm{Cu}$-based RTDs reported in previous literature and was comparable to that of the commercial Pt-based one. Moreover, the sensitivity of the Ni-based RTDs was independent of the electrode shape and the reference 
resistance, which is advantageous in practical application by offering design flexibility. The bending test and the tape-pull test confirmed the superior mechanical and electrical stability of the flexible RTDs. This novel yet simple LDP process for the generation of the Ni-based flexible RTDs offers a new way to replace conventional fabrication methods and materials.

Supplementary Materials: The following are available online at https:/ / www.mdpi.com/2079-499 1/11/3/576/s1, Video S1: Laser digital patterning processing, Video S2: Washing process, Video S3: Response to gloved-finger touching, Video S4: Immerse in cold tap water and seawater, Video S5: Tape-pull test.

Author Contributions: Conceptualization, methodology, formal analysis, data curation, writingoriginal draft, V.B.N.; conceptualization, methodology, investigation, supervision, funding acquisition, writing - review and editing, D.L. All authors have read and agreed to the published version of the manuscript.

Funding: This work was financially supported by the National Research Foundation of Korea (NRF) grant funded by the Korea government (MSIT) (No. 2018R1D1A1B07042735), and by the Korea Institute of Energy Technology Evaluation and Planning (KETEP) and the Ministry of Trade, Industry and Energy (MOTIE) of the Republic of Korea (No. 20194030202440).

Acknowledgments: The authors express their gratitude to the staffs in Korea Advanced Nano Fab Center (KANC) for support with SEM, AFM, EDX, and TEM analysis.

Conflicts of Interest: The authors declare no conflict of interest.

\section{References}

1. Kim, J.; Kim, J.; Shin, Y.; Yoon, Y. A study on the fabrication of an RTD (resistance temperature detector) by using Pt thin film. Korean J. Chem. Eng. 2001, 18, 61-66. [CrossRef]

2. Eom, T.H.; Han, J.I. The effect of the nickel and chromium concentration ratio on the temperature coefficient of the resistance of a Ni-Cr thin film-based temperature sensor. Sens. Actuators A Phys. 2017, 260, 198-205. [CrossRef]

3. Sarma, S.; Lee, J.H. Developing Efficient Thin Film Temperature Sensors Utilizing Layered Carbon Nanotube Films. Sensors 2018, 18, 3182. [CrossRef]

4. El-Shimy, H.; Arai, F.; Fukuda, T. Three-dimensional nano temperature sensors fabricated using focused ion beam chemical vapour deposition. In Proceedings of the 2006 Sixth IEEE Conference on Nanotechnology, Cincinnati, OH, USA, 17-20 July 2006; pp. 770-772.

5. Lee, C.-Y.; Lin, C.-H.; Lo, Y.-M. Fabrication of a Flexible Micro Temperature Sensor for Micro Reformer Applications. Sensors 2011, 11, 3706-3716. [CrossRef]

6. Zribi, A.; Barthès, M.; Bégot, S.; Lanzetta, F.; Rauch, J.Y.; Moutarlier, V. Design, fabrication and characterization of thin film resistances for heat flux sensing application. Sens. Actuators A Phys. 2016, 245, 26-39. [CrossRef]

7. Nguyen, D.K.; Kim, T. Graphene quantum dots produced by exfoliation of intercalated graphite nanoparticles and their application for temperature sensors. Appl. Surf. Sci. 2018, 427, 1152-1157. [CrossRef]

8. Santos, E.J.; Vasconcelos, I.B. RTD-based smart temperature sensor: Process development and circuit design. In Proceedings of the 2008 26th International Conference on Microelectronics, Nis, Serbia, 11-14 May 2008; pp. 333-336.

9. Chani, M.T.S.; Asiri, A.M.; Karimov, K.S.; Niaz, A.K.; Khan, S.B.; Alamry, K.A. Aluminium phthalocyanine chloride thin films for temperature sensing. Chin. Phys. B 2013, 22, 118101. [CrossRef]

10. Kwon, J.; Suh, Y.D.; Lee, J.; Lee, P.; Han, S.; Hong, S.; Yeo, J.; Lee, H.; Ko, S.H. Recent progress in silver nanowire based flexible/wearable optoelectronics. J. Mat. Chem. C 2018, 6, 7445-7461. [CrossRef]

11. Kim, N.; Kwon, J.; Jung, J.; Kim, K.; Lee, H.; Yeo, J.; Hong, S.; Han, S.; Ko, S.H. A Transparent and Flexible Capacitive-Force Touch Pad from High-Aspect-Ratio Copper Nanowires with Enhanced Oxidation Resistance for Applications in Wearable Electronics. Small Methods 2018, 2, 1800077. [CrossRef]

12. Park, J.H.; Han, S.; Kim, D.; You, B.K.; Joe, D.J.; Hong, S.; Seo, J.; Kwon, J.; Jeong, C.K.; Park, H.-J.; et al. Plasmonic-Tuned Flash Cu Nanowelding with Ultrafast Photochemical-Reducing and Interlocking on Flexible Plastics. Adv. Funct. Mat. 2017, $27,1701138$. [CrossRef]

13. Someya, T.; Sekitani, T.; Iba, S.; Kato, Y.; Kawaguchi, H.; Sakurai, T. A large-area, flexible pressure sensor matrix with organic field-effect transistors for artificial skin applications. Proc. Natl. Acad. Sci. USA 2004, 101, 9966-9970. [CrossRef]

14. Honda, W.; Harada, S.; Arie, T.; Akita, S.; Takei, K. Wearable, Human-Interactive, Health-Monitoring, Wireless Devices Fabricated by Macroscale Printing Techniques. Adv. Funct. Mat. 2014, 24, 3299-3304. [CrossRef]

15. Nam, V.B.; Lee, D. Copper nanowires and their applications for flexible, transparent conducting films: A review. Nanomaterials 2016, 6, 47. [CrossRef] 
16. Yang, Y.; Han, J.; Huang, J.; Sun, J.; Wang, Z.L.; Seo, S.; Sun, Q. Stretchable Energy-Harvesting Tactile Interactive Interface with Liquid-Metal-Nanoparticle-Based Electrodes. Adv. Funct. Mat. 2020, 30, 1909652. [CrossRef]

17. Lee, E.K.; Yoo, H.; Lee, C.H. Advanced Materials and Assembly Strategies for Wearable Biosensors: A Review. In Biosensor-Current and Novel Strategies for Biosensing; IntechOpen: London, UK, 2020. [CrossRef]

18. Kim, M.; Seo, S. Flexible pressure and touch sensor with liquid metal droplet based on gallium alloys. Mol. Cryst. Liq. Cryst. 2019, 685, 40-46. [CrossRef]

19. Yoon, S.; Kim, H.-K. Cost-effective stretchable Ag nanoparticles electrodes fabrication by screen printing for wearable strain sensors. Surf. Coat. Technol. 2020, 384, 125308. [CrossRef]

20. Yeo, J.; Hong, S.; Lee, D.; Hotz, N.; Lee, M.-T.; Grigoropoulos, C.P.; Ko, S.H. Next Generation Non-Vacuum, Maskless, Low Temperature Nanoparticle Ink Laser Digital Direct Metal Patterning for a Large Area Flexible Electronics. PLoS ONE 2012, 7, e42315. [CrossRef]

21. Ko, S.H.; Pan, H.; Lee, D.; Grigoropoulos, C.P.; Park, H.K. Nanoparticle Selective Laser Processing for a Flexible Display Fabrication. Jpn. J. Appl. Phys. 2010, 49, 05EC03. [CrossRef]

22. Lee, M.-T.; Lee, D.; Sherry, A.; Grigoropoulos, C.P. Rapid selective metal patterning on polydimethylsiloxane (PDMS) fabricated by capillarity-assisted laser direct write. J. Micromech. Microeng. 2011, 21, 095018. [CrossRef]

23. Paeng, D.; Yeo, J.; Lee, D.; Moon, S.-J.; Grigoropoulos, C.P. Laser wavelength effect on laser-induced photo-thermal sintering of silver nanoparticles. Appl. Phys. A 2015, 120, 1229-1240. [CrossRef]

24. Lee, D.; Pan, H.; Sherry, A.; Ko, S.H.; Lee, M.-T.; Kim, E.; Grigoropoulos, C.P. Large-area nanoimprinting on various substrates by reconfigurable maskless laser direct writing. Nanotechnology 2012, 23, 344012. [CrossRef]

25. Shin, J.; Jeong, B.; Kim, J.; Nam, V.B.; Yoon, Y.; Jung, J.; Hong, S.; Lee, H.; Eom, H.; Yeo, J. Sensitive Wearable Temperature Sensor with Seamless Monolithic Integration. Adv. Mat. 2019, 32, 1905527. [CrossRef]

26. Nam, V.B.; Giang, T.T.; Koo, S.; Rho, J.; Lee, D. Laser digital patterning of conductive electrodes using metal oxide nanomaterials. Nano Converg. 2020, 7, 1-17. [CrossRef] [PubMed]

27. Kim, D.H.; Lee, H.S.; Kim, Y.-M.; Kim, J.E.; Suh, K.S.; Kim, S.-C.; Kim, T. Large-Scale Laser Patterning of Silver Nanowire Network by Using Patterned Optical Mirror Mask. Sci. Adv. Mat. 2016, 8, 1369-1373. [CrossRef]

28. Ryu, H.S.; Kim, H.-S.; Kim, D.; Lee, S.J.; Choi, W.; Kwon, S.J.; Han, J.-H.; Cho, E.-S. Understanding of the Mechanism for Laser Ablation-Assisted Patterning of Graphene/ITO Double Layers: Role of Effective Thermal Energy Transfer. Micromachines 2020, 11, 821. [CrossRef]

29. Zhou, W.; Yu, Y.; Bai, S.; Hu, A. Laser direct writing of waterproof sensors inside flexible substrates for wearable electronics. Opt. Laser Technol. 2021, 135, 106694. [CrossRef]

30. Min, H.; Lee, B.; Jeong, S.; Lee, M. Fabrication of $10 \mu \mathrm{m}$-scale conductive Cu patterns by selective laser sintering of Cu complex ink. Opt. Laser Technol. 2017, 88, 128-133. [CrossRef]

31. Min, H.; Lee, B.; Jeong, S.; Lee, M. Laser-direct process of $\mathrm{Cu}$ nano-ink to coat highly conductive and adhesive metallization patterns on plastic substrate. Opt. Lasers Eng. 2016, 80, 12-16. [CrossRef]

32. Wang, X.; Zhang, J.; Mei, X.; Xu, B.; Miao, J. Laser fabrication of fully printed graphene oxide microsensor. Opt. Lasers Eng. 2021, 140, 106520. [CrossRef]

33. An, K.; Hong, S.; Han, S.; Lee, H.; Yeo, J.; Ko, S.H. Selective Sintering of Metal Nanoparticle Ink for Maskless Fabrication of an Electrode Micropattern Using a Spatially Modulated Laser Beam by a Digital Micromirror Device. ACS Appl. Mat. Interfaces 2014, 6, 2786-2790. [CrossRef]

34. Heo, M.; Cho, H.; Jung, J.-W.; Jeong, J.-R.; Park, S.; Kim, J.Y. High-Performance Organic Optoelectronic Devices Enhanced by Surface Plasmon Resonance. Adv. Mat. 2011, 23, 5689-5693. [CrossRef] [PubMed]

35. Peng, Z.; Spliethoff, B.; Tesche, B.; Walther, T.; Kleinermanns, K. Laser-Assisted Synthesis of Au-Ag Alloy Nanoparticles in Solution. J. Phys. Chem. B 2006, 110, 2549-2554. [CrossRef]

36. Ahn, C.H.; Park, H.W.; Kim, H.H.; Park, S.H.; Son, C.; Kim, M.C.; Lee, J.H.; Go, J.S. Direct fabrication of thin film gold resistance temperature detection sensors on a curved surface using a flexible dry film photoresist and their calibration up to $450{ }^{\circ} \mathrm{C}$. $J$. Micromech. Microeng. 2013, 23, 065031. [CrossRef]

37. Huang, H.; Li, H.; Feng, J.-J.; Wang, A.-J. One-step green synthesis of fluorescent bimetallic Au/Ag nanoclusters for temperature sensing and in vitro detection of Fe 3+. Sens. Actuators B Chem. 2016, 223, 550-556. [CrossRef]

38. Ali, S.; Hassan, A.; Bae, J.; Lee, C.H.; Kim, J. All-Printed Differential Temperature Sensor for the Compensation of Bending Effects. Langmuir 2016, 32, 11432-11439. [CrossRef]

39. Han, B.; Hou, X.; Xiang, R.; He, G. Synthesis of highly luminescent Cu/Ag bimetal nanoclusters and their application in a temperature sensor. Anal. Methods 2017, 9, 4028-4032. [CrossRef]

40. Yang, X.; Lu, Y.; Duan, L.; Liu, B.; Yao, J. Temperature Sensor Based on Hollow Fiber Filled with Graphene-Ag Composite Nanowire and Liquid. Plasmonics 2017, 12, 1805-1811. [CrossRef]

41. Lee, D.; Pan, H.; Ko, S.H.; Park, H.K.; Kim, E.; Grigoropoulos, C.P. Non-vacuum, single-step conductive transparent ZnO patterning by ultra-short pulsed laser annealing of solution-deposited nanoparticles. Appl. Phys. A 2012, 107, 161-171. [CrossRef]

42. Paeng, D.; Lee, D.; Yeo, J.; Yoo, J.-H.; Allen, F.I.; Kim, E.; So, H.; Park, H.K.; Minor, A.M.; Grigoropoulos, C.P. Laser-Induced Reductive Sintering of Nickel Oxide Nanoparticles under Ambient Conditions. J. Phys. Chem. C 2015, 119, 6363-6372. [CrossRef] 
43. Han, S.; Hong, S.; Yeo, J.; Kim, D.; Kang, B.; Yang, M.-Y.; Ko, S.H. Nanorecycling: Monolithic Integration of Copper and Copper Oxide Nanowire Network Electrode through Selective Reversible Photothermochemical Reduction. Adv. Mat. 2015, 27, 6397-6403. [CrossRef] [PubMed]

44. Mizoshiri, M.; Arakane, S.; Sakurai, J.; Hata, S. Direct writing of Cu-based micro-temperature detectors using femtosecond laser reduction of $\mathrm{CuO}$ nanoparticles. Appl. Phys. Express 2016, 9, 36701. [CrossRef]

45. Mizoshiri, M.; Ito, Y.; Arakane, S.; Sakurai, J.; Hata, S. Direct fabrication of $\mathrm{Cu} / \mathrm{Cu} 2 \mathrm{O}$ composite micro-temperature sensor using femtosecond laser reduction patterning. Jpn. J. Appl. Phys. 2016, 55, 06GP05. [CrossRef]

46. Qunshuang, M.; Haozhe, C.; Hui, Z.; Wei, M.; Lei, H.; Huadong, L.; Yitao, W.; Xiaohui, Y. The alloying effects of Cr on in-situ phase evolution and wear resistance of nickel composite coatings fabricated by wide-band laser deposition. Surf. Coat. Technol. 2020, 397, 126019. [CrossRef]

47. Jena, G.; Thinaharan, C.; George, R.; Philip, J. Robust nickel-reduced graphene oxide-myristic acid superhydrophobic coating on carbon steel using electrochemical codeposition: Effect of deposition current density and electrolyte temperature on superhydrophobicity and corrosion resistance. Surf. Coat. Technol. 2020, 397, 125942. [CrossRef]

48. Daugherty, R.E.; Zumbach, M.M.; Sanders, S.F.; Golden, T.D. Design challenges in electrodepositing metal-anionic clay nanocomposites: Synthesis, characterization, and corrosion resistance of nickel-LDH nanocomposite coatings. Surf. Coat. Technol. 2018, 349, 773-782. [CrossRef]

49. Kuphaldt, T.R. Lessons in Electric Circuits, Volume I-DC, 5th ed.; Open Book Project: Lansing, MI, USA, 2006.

50. Turkani, V.S.; Maddipatla, D.; Narakathu, B.B.; Altay, B.N.; Fleming, P.D.; Bazuin, B.J.; Atashbar, M.Z. Nickel Based RTD Fabricated via Additive Screen Printing Process for Flexible Electronics. IEEE Access 2019, 7, 37518-37527. [CrossRef]

51. Jeon, J.; Lee, H.-B.-R.; Bao, Z. Flexible Wireless Temperature Sensors Based on Ni Microparticle-Filled Binary Polymer Composites. Adv. Mat. 2012, 25, 850-855. [CrossRef]

52. Ma, B.; Ren, J.; Deng, J.; Yuan, W. Flexible thermal sensor array on PI film substrate for underwater applications. In Proceedings of the 2010 IEEE 23rd International Conference on Micro Electro Mechanical Systems (MEMS), Hong Kong, China, 24-28 January 2010; pp. 679-682.

53. Nam, V.B.; Shin, J.; Yoon, Y.; Giang, T.T.; Kwon, J.; Suh, Y.D.; Yeo, J.; Hong, S.; Ko, S.H.; Lee, D. Highly Stable Ni-Based Flexible Transparent Conducting Panels Fabricated by Laser Digital Patterning. Adv. Funct. Mat. 2019, 29, 1806895. [CrossRef]

54. Jiang, F.; Choy, W.C.; Li, X.; Zhang, D.; Cheng, J. Post-treatment-Free Solution-Processed Non-stoichiometric NiOx Nanoparticles for Efficient Hole-Transport Layers of Organic Optoelectronic Devices. Adv. Mat. 2015, 27, 2930-2937. [CrossRef]

55. Lee, H.; Yang, M. Effect of solvent and PVP on electrode conductivity in laser-induced reduction process. Appl. Phys. A 2015, 119, 317-323. [CrossRef]

56. Ryu, J.; Kim, H.-S.; Hahn, H.T. Reactive Sintering of Copper Nanoparticles Using Intense Pulsed Light for Printed Electronics. J. Electron. Mat. 2010, 40, 42-50. [CrossRef]

57. Coburn, J.C.; Pottiger, M.T. Thermal curing in polyimide films and coatings. In Polyimides; CRC Press: Boca Raton, FL, USA, 2018; pp. 207-248.

58. Numata, S.; Kinjo, N.; Makino, D. Chemical structures and properties of low thermal expansion coefficient polyimides. Polym. Eng. Sci. 1988, 28, 906-911. [CrossRef]

59. Hwang, J.-W. Thermal Expansion of Nickel and Iron and the Influence of Nitrogen on the Lattice Parameter of Iron at the Curie Temperature. Master's Thesis, Missouri University of Science and Technology, Rolla, MO, USA, 1972.

60. Yang, J.; Wei, D.; Tang, L.; Song, X.; Luo, W.; Chu, J.; Gao, T.; Shi, H.; Du, C. Wearable temperature sensor based on graphene nanowalls. Rsc Adv. 2015, 5, 25609-25615. [CrossRef]

61. Kuo, J.T.; Yu, L.; Meng, E. Micromachined thermal flow sensors-A review. Micromachines 2012, 3, 550-573. [CrossRef]

62. Yokota, T.; Inoue, Y.; Terakawa, Y.; Reeder, J.; Kaltenbrunner, M.; Ware, T.; Yang, K.; Mabuchi, K.; Murakawa, T.; Sekino, M.; et al. Ultraflexible, large-area, physiological temperature sensors for multipoint measurements. Proc. Natl. Acad. Sci. USA 2015, 112, 14533-14538. [CrossRef] [PubMed] 